\title{
Gut microbiota: next frontier in understanding human health and development of biotherapeutics
}

This article was published in the following Dove Press journal:

Biologics:Targets and Therapy

8 July 2011

Number of times this article has been viewed

\section{Satya Prakash \\ Laetitia Rodes \\ Michael Coussa-Charley \\ Catherine Tomaro- \\ Duchesneau \\ Biomedical Technology and Cell \\ Therapy Research Laboratory, \\ Department of Biomedical \\ Engineering and Artificial Cells and Organs Research Centre, Faculty of Medicine, McGill University, Montreal, Quebec, Canada}

\begin{abstract}
The gut microbiota is a remarkable asset for human health. As a key element in the development and prevention of specific diseases, its study has yielded a new field of promising biotherapeutics. This review provides comprehensive and updated knowledge of the human gut microbiota, its implications in health and disease, and the potentials and limitations of its modification by currently available biotherapeutics to treat, prevent and/ or restore human health, and future directions. Homeostasis of the gut microbiota maintains various functions which are vital to the maintenance of human health. Disruption of the intestinal ecosystem equilibrium (gut dysbiosis) is associated with a plethora of human diseases, including autoimmune and allergic diseases, colorectal cancer, metabolic diseases, and bacterial infections. Relevant underlying mechanisms by which specific intestinal bacteria populations might trigger the development of disease in susceptible hosts are being explored across the globe. Beneficial modulation of the gut microbiota using biotherapeutics, such as prebiotics, probiotics, and antibiotics, may favor health-promoting populations of bacteria and can be exploited in development of biotherapeutics. Other technologies, such as development of human gut models, bacterial screening, and delivery formulations eg, microencapsulated probiotics, may contribute significantly in the near future. Therefore, the human gut microbiota is a legitimate therapeutic target to treat and/or prevent various diseases. Development of a clear understanding of the technologies needed to exploit the gut microbiota is urgently required.
\end{abstract}

Keywords: gut microbiota, human health, dysbiosis, biotherapeutics, probiotics, microencapsulation

\section{Introduction}

The human gastrointestinal tract houses a huge microbial ecosystem, the gut microbiota. This intestinal ecosystem is partially responsible for maintaining human health. However, particular changes in the ecosystem might contribute to the development of certain diseases. With this in mind, there is a need for an exhaustive review on the functions of the gut microbiota, occurrence of gut dysbiosis (alteration of the microbiota), mechanisms by which intestinal bacteria can trigger development of disease, how this ecosystem can be exploited for understanding human health, development of biotherapeutics, expert opinion on current biotherapeutics, and future perspectives. This review presents a descriptive and comprehensive analysis on "the good, the bad, and the ugly" of the gut microbiota, and methods to study these and their modulation of human health. 


\section{Composition}

The human gut microbiota represents the trillions of microorganisms located in our intestines. Collectively, the number of intestinal microbial cells is 10 times greater than the number of human body cells. ${ }^{1}$ It was recently demonstrated that the microbiome, which represents the collective genomes of the gut microbiota, is approximately 150 times larger than the human gene complement, with an estimated set of 3.3 million microbial genes. ${ }^{2}$ Seven bacterial divisions constitute the gut microbiota, ie, Firmicutes, Bacteroides, Proteobacteria, Fusobacteria, Verrucomicrobia, Cyanobacteria, and Actinobacteria, with Firmicutes and Bacteroides being the most abundant species. ${ }^{3}$ Bacterial communities exhibit quantitative and qualitative variations along the length of the gastrointestinal tract due to host factors (eg, $\mathrm{pH}$, transit time, bile acids, digestive enzymes, and mucus), nonhost factors (eg, nutrients, medication, and environmental factors), and bacterial factors (eg, adhesion capacity, enzymes, and metabolic capacity). ${ }^{4}$

\section{Acquisition}

It is generally accepted that humans are born with a sterile gut. However, new evidence suggests that colonization of the gastrointestinal tract starts before birth, with the fetus ingesting amniotic fluid containing microbes. ${ }^{5}$ Subsequently, intestinal colonization is acquired during the first months of life, with aerobic and facultative anaerobic colonization, followed by obligate anaerobes and Bifidobacteria. ${ }^{6}$ Establishment of the gut microbiota is recognized as a complex process influenced by factors at the level of the host and of the microbes themselves. $^{3}$

\section{Exploration}

Study of the composition of human colonic microbiota and metabolism has methodological and ethical limitations. Attempts to circumvent these limitations have led to the development of models. In vitro models are of interest for ecological, fermentation, and metabolic studies. ${ }^{7}$ These provide reproducible results and controlled mechanistic studies (Table 1). Fecal inocula are most often utilized as a representation of the intestinal microbiota. ${ }^{2}$ In vivo models for the exploration of the gut microbiota encompass various species of laboratory animals. Effects of the indigenous microbiota on the host have been determined by gnotobiology, ie, selective colonization of germ-free animals with defined organisms. ${ }^{8}$

\section{Analysis}

Until recently, the analysis of bacterial ecosystems was performed by growth on defined media, which has some limitations because this method is labor-intensive and, more importantly, only $80 \%$ of stool bacteria can be cultivated. ${ }^{6,8}$ As a consequence, new molecular techniques have been developed. In terms of qualitative measurements of the microbiota, techniques such as fingerprinting (denaturing gradient gel electrophoresis), terminal restriction fragment length polymorphism, ribosomal intergenic spacer analysis, and $16 \mathrm{~S}$ ribosomal RNA sequencing are widely used..$^{8-11}$ Specifically, genome sequencing has provided tremendous information in the microbial world, spearheading technologies such as microarrays. ${ }^{8} \mathrm{New}$ automated parallel sequencing technologies, based on the $16 \mathrm{~S}$ ribosomal RNA gene present in all prokaryotes, can offer a cost-effective solution for rapid sequencing and identification of bacterial species of the gut. Prominent high-throughput sequencing technologies include 454 Life Sciences' Genome Sequencer ${ }^{\mathrm{TM}}$, Applied Biosystems' SOLiD ${ }^{\mathrm{TM}} 3$ Plus system, Illumina's Genome Analyzer IIx, and other technologies developed by Affymetrix, Helicos, Qiagen, and Microchip. For quantitative measurements of the gut microbiota, fluorescence in situ hybridization, catalyzed reporter deposition-fluorescence in situ hybridization, quantitative polymerase chain reaction, and scanning electron microscopy in situ hybridization, can be useful. ${ }^{810-12}$ Fluorescence in situ hybridization allows for the visualization of microorganisms in their natural environment using labeled probes specific for selected bacteria. This method has been used for the determination of changes in the bacterial populations of fecal homogenates and in tissue sections from individuals with certain diseases. Catalyzed reporter deposition-fluorescence in situ hybridization is a modified method of fluorescence in situ hybridization which allows for in situ amplification using horseradish peroxidase, enhancing bacterial cell detection in samples where ribosomal RNA is insufficient for fluorescence in situ hybridization. ${ }^{12}$ Real-time quantitative polymerase chain reaction is a recent and widely used technique for exploration of the roles of gut microflora in health and disease, based on the presence of specific RNA sequences. There is also scanning electron microscopic in situ hybridization which uses deposition of nanogold particles to enable detection ${ }^{12}$ (Table 2). Finally, metagenomics is an approach to analyze the genomic content of microbial communities living in a particular niche, such as the gut, and for identifying and quantifying the bacterial species present. ${ }^{8}$ 
Table I In vitro and in vivo models of the human gut microbiota and their potentials and limitations

\begin{tabular}{|c|c|c|c|c|}
\hline Models & Description & Main use & Limitations & References \\
\hline \multicolumn{5}{|l|}{ In vitro } \\
\hline Static batch system & $\begin{array}{l}\text { Fresh feces or colonic contents } \\
\text { suspended in buffer solution }\end{array}$ & $\begin{array}{l}\text { Short-term metabolic and } \\
\text { enzymatic studies }\end{array}$ & $\begin{array}{l}\text { Rapid change in ecosystem } \\
\text { composition }\end{array}$ & 7 \\
\hline $\begin{array}{l}\text { Semicontinuous batch } \\
\text { system }\end{array}$ & $\begin{array}{l}\text { Chemostat culture system of } \\
\text { semicontinuous flow } \\
\text { Inoculated with defined bacteria, feces, } \\
\text { or colonic content }\end{array}$ & $\begin{array}{l}\text { Long-term studies on } \\
\text { metabolic, ecologic, and } \\
\text { dietary fermentation }\end{array}$ & $\begin{array}{l}\text { Host factors are ignored } \\
\text { Stability of ecosystem is } \\
\text { assumed }\end{array}$ & 7 \\
\hline $\begin{array}{l}\text { Continuous batch } \\
\text { system }\end{array}$ & $\begin{array}{l}\text { Chemostat culture system of } \\
\text { continuous flow } \\
\text { Inoculated with defined bacteria, feces, } \\
\text { or colonic content }\end{array}$ & $\begin{array}{l}\text { Long-term studies on } \\
\text { metabolic, ecologic, and } \\
\text { dietary features of } \mathrm{Gl} \\
\text { microbiota }\end{array}$ & $\begin{array}{l}\text { Host factors are ignored } \\
\text { Complex system to set up } \\
\text { Stability of ecosystem is } \\
\text { assumed }\end{array}$ & $7,105,106$ \\
\hline \multicolumn{5}{|l|}{ In vivo } \\
\hline Laboratory animals & $\begin{array}{l}\text { Fresh feces or colonic contents from } \\
\text { conventional microbiota animals }\end{array}$ & $\begin{array}{l}\text { Metabolic, ecological, and } \\
\text { preclinical studies }\end{array}$ & $\begin{array}{l}\text { Differences between animals } \\
\text { and humans gut microbiota } \\
\text { composition }\end{array}$ & $7,109,112$ \\
\hline Gnobiotic animals & $\begin{array}{l}\text { Germ-free laboratory animals colonized } \\
\text { with defined organisms or transferred } \\
\text { microbiota from a laboratory animal or } \\
\text { a human volunteer }\end{array}$ & $\begin{array}{l}\text { Host-bacterial and bacterial- } \\
\text { bacterial interaction studies }\end{array}$ & $\begin{array}{l}\text { Alteration of bacterial } \\
\text { interactions }\end{array}$ & $7,10,49$ \\
\hline Human volunteers & $\begin{array}{l}\text { Fresh feces or colonic contents from } \\
\text { human volunteers }\end{array}$ & $\begin{array}{l}\text { Metabolic, ecological, } \\
\text { chemical, and clinical studies }\end{array}$ & $\begin{array}{l}\text { Ethical issues } \\
\text { Relevance of feces/colonic } \\
\text { contents to represent the } \\
\text { overall Gl microbiota }\end{array}$ & $7,36,42$ \\
\hline
\end{tabular}

Abbreviation: $\mathrm{Gl}$, gastrointestinal.

\section{The good}

The gut microbiota performs essential functions in maintenance of health, including having protective, structural, and metabolic roles.

\section{Essential metabolic functions}

Metabolic functions of the gut microbiota include production of vitamin, amino acid synthesis, and bile acid biotransformation. Bile acid biotransformations, performed by microbial enzymes, have implications for cholesterol and glucose metabolism. ${ }^{13}$ Importantly, the microbiome provides biochemical pathways required for the fermentation of nondigestible substrates and endogenous mucus. Through fermentation, bacterial growth is stimulated, producing shortchain fatty acids and gases. ${ }^{14}$ The major short-chain fatty acids produced are acetate, butyrate, and propionate. Other bacterial end products include lactate, ethanol, succinate, formate, valerate, caproate, isobutyrate, 2-methyl-butyrate, and isovalerate. Bacterial fermentation is present in the cecum and colon, where the short-chain fatty acids are absorbed, stimulating the absorption of salts and water. One property of short-chain fatty acids is their trophic effect on the intestinal epithelium. ${ }^{14}$ Butyrate is the preferred energy source for epithelial cells, and is almost entirely cleared by the colonic epithelium. Acetate is the principal short-chain fatty acid in the colon and the primary substrate for cholesterol synthesis. Finally, propionate supplementation in the diet was shown to reduce cholesterol levels in vivo. ${ }^{15,16}$ Clinical trials have yet to confirm these observations. Therefore, the metabolic activities performed by the gut microbiota are various and essential for host metabolism (Figure 1).

\section{Ensures protection}

Pathogen displacement or "colonization resistance" is an accepted function of the gut microbiota. Commensal organisms prevent pathogenic colonization by competing for attachment sites and nutrients, and also through the production and secretion of antimicrobials. Those mechanisms are relevant for reducing the level of lipopolysaccharides, peptidoglycans, bacterial CpG-DNA motifs, and superantigens, which can all be detrimental to the host. ${ }^{17}$ The indigenous microbiota is also essential for development of the immune system. ${ }^{18}$ Germ-free mice display underdeveloped lymphatic systems, with fewer Peyer's patches and isolated lymphoid follicles. ${ }^{19,20}$ Moreover, intestinal dendritic cells are fewer in germ-free animals, and there is evidence to support a role for bacterial signals in B cell development. ${ }^{21,22}$ Furthermore, signals from intestinal bacteria appear important for the development of regulatory $\mathrm{T}$, $\mathrm{T}$ helper type 1 and 2 cells, and T helper 17 cells. ${ }^{23-25}$ The first commensal 
Table 2 Available techniques for human gut microbiota characterization

\begin{tabular}{|c|c|c|c|c|}
\hline Techniques & Description & Main use & Limitations & Reference \\
\hline Culture-based & $\begin{array}{l}\text { Defined media used to isolate bacterial } \\
\text { populations }\end{array}$ & $\begin{array}{l}\text { Quantification/characterization } \\
\text { of isolated colonies }\end{array}$ & $\begin{array}{l}\text { Bacteria uncultivable } \\
\text { Species/strains level hardly } \\
\text { detected } \\
\text { Labor-intensive }\end{array}$ & 8,6 \\
\hline $\begin{array}{l}\text { I6S rRNA } \\
\text { sequencing }\end{array}$ & Species/strains level sequencing & Bacterial identification & Extensive data analysis & $8,9-11$ \\
\hline DGGE & $\begin{array}{l}\text { Denaturation of small PCR amplicons } \\
\text { from extracted community DNA and } \\
\text { gel migration }\end{array}$ & Comparative studies & $\begin{array}{l}\text { PCR amplicons too small to } \\
\text { sequence information }\end{array}$ & 8,11 \\
\hline Terminal RFLP & $\begin{array}{l}\text { Denaturation of full-length } 16 \mathrm{~S} \text { rRNA } \\
\text { PCR amplicons from extracted } \\
\text { community DNA and gel migration }\end{array}$ & Communities comparison & $\begin{array}{l}\text { Limited taxonomic } \\
\text { resolution }\end{array}$ & 8,11 \\
\hline RIS analysis & $\begin{array}{l}\text { PCR amplification of IS region between } \\
\text { I6S-23S rRNA genes hybridized to } \\
\text { fluorescently labeled primers }\end{array}$ & $\begin{array}{l}\text { Characterization of complex } \\
\text { bacterial communities }\end{array}$ & $\begin{array}{l}\text { Complex bacterial } \\
\text { identification } \\
\text { Lack of extensive database }\end{array}$ & 8,11 \\
\hline FISH & $\begin{array}{l}\text { Hybridization of fluorescently labeled } \\
\text { oligonucleotide probes to I6S rRNA } \\
\text { specific of targeted bacteria }\end{array}$ & $\begin{array}{l}\text { Quantification of targeted } \\
\text { bacterial groups/species }\end{array}$ & $\begin{array}{l}\text { Novel species/strains } \\
\text { unidentified }\end{array}$ & $8,10,11$ \\
\hline CARD-FISH & $\begin{array}{l}\text { Modified FISH method: in situ } \\
\text { amplification using horseradish } \\
\text { peroxidase }\end{array}$ & $\begin{array}{l}\text { Bacteria quantification if FISH } \\
\text { inadequate }\end{array}$ & $\begin{array}{l}\text { Novel species/strains } \\
\text { unidentified }\end{array}$ & 12 \\
\hline $\begin{array}{l}\text { SEM in situ } \\
\text { hybridization }\end{array}$ & $\begin{array}{l}\text { Combination of in situ hybridization } \\
\text { and SEM }\end{array}$ & $\begin{array}{l}\text { Quantification of targeted } \\
\text { bacterial groups/species }\end{array}$ & $\begin{array}{l}\text { Novel species/strains } \\
\text { unidentified }\end{array}$ & 12 \\
\hline Quantitative PCR & $\begin{array}{l}\text { Specific bacterial groups/species } \\
\text { targeted from a mix culture by } \\
\text { quantitative PCR primers }\end{array}$ & $\begin{array}{l}\text { Quantitative studies of } \\
\text { complex system }\end{array}$ & $\begin{array}{l}\text { Novel species/strains } \\
\text { unidentified } \\
\text { Strain required for standard } \\
\text { curve }\end{array}$ & $8,10,11$ \\
\hline DNA microarray & $\begin{array}{l}\text { Set of regular arranged spots of DNA } \\
\text { recognition elements positioned on } \\
\text { microscopic slides }\end{array}$ & $\begin{array}{l}\text { Screening of human gut } \\
\text { microbial communities }\end{array}$ & $\begin{array}{l}\text { Low detection limit } \\
\text { Hybridization biases } \\
\text { Novel species/strains } \\
\text { unidentified }\end{array}$ & 8 \\
\hline
\end{tabular}

Abbreviations: CARD, catalyzed reporter deposition; DGGE, denaturing gradient gel electrophoresis; FISH, fluorescence in situ hybridization; ISR, intergenic spacer; PCR, polymerase chain reaction; RFLP, restriction fragment length polymorphism; R, ribosomal; SEM, scanning electron microscopy.

microorganism molecule shown to influence an immune response beneficially was capsular polysaccharide A, produced by Bacteroides fragilis. ${ }^{26}$ Short-chain fatty acids, such as butyrate, may also exert potent immunomodulatory effects by suppressing nuclear factor-kB activation and/or by acting on G-coupled receptors, as demonstrated with acetate..$^{27,28}$ These concepts illustrate a dynamic relationship between the immune system and the microbiota. The intestinal mucosa averts threats by signaling to the innate immune system through pattern recognition receptors, such as toll-like receptors. Pattern recognition receptors recognize and bind to specific microbial macromolecules, referred to as microbial-associated molecular patterns. These include lipopolysaccharide, flagellin, peptidoglycan, and $\mathrm{N}$-formylated peptides. In the intestinal mucosa, activation of pattern recognition receptors initiates nuclear factor-kB pathways, mitogen-activated protein kinase, and caspasedependent signaling cascades. These lead to the production and release of protective peptides, cytokines, chemokines, and phagocytes. The result can be a protective response to commensal bacteria, an inflammatory response to pathogenic organisms, or a trigger of apoptosis. Therefore, commensal bacteria of the gastrointestinal tract play active roles in the development and homeostasis of the immune system, as shown in Figure 1.

\section{Structural and histological function}

The microbiota ensures intestinal structure and function. Firstly, the mucus layer, which reflects the balance between mucus secretion and bacterial degradation, constitutes an obstacle to the uptake of antigens and proinflammatory molecules. ${ }^{29}$ There is evidence indicating that butyrate reinforces the colonic defense barrier by inducing the secretion of mucins, trefoil factors, and antimicrobial peptides. ${ }^{30}$ Secondly, some bacterial communities may strengthen the barrier at the level of the tight junctions, 


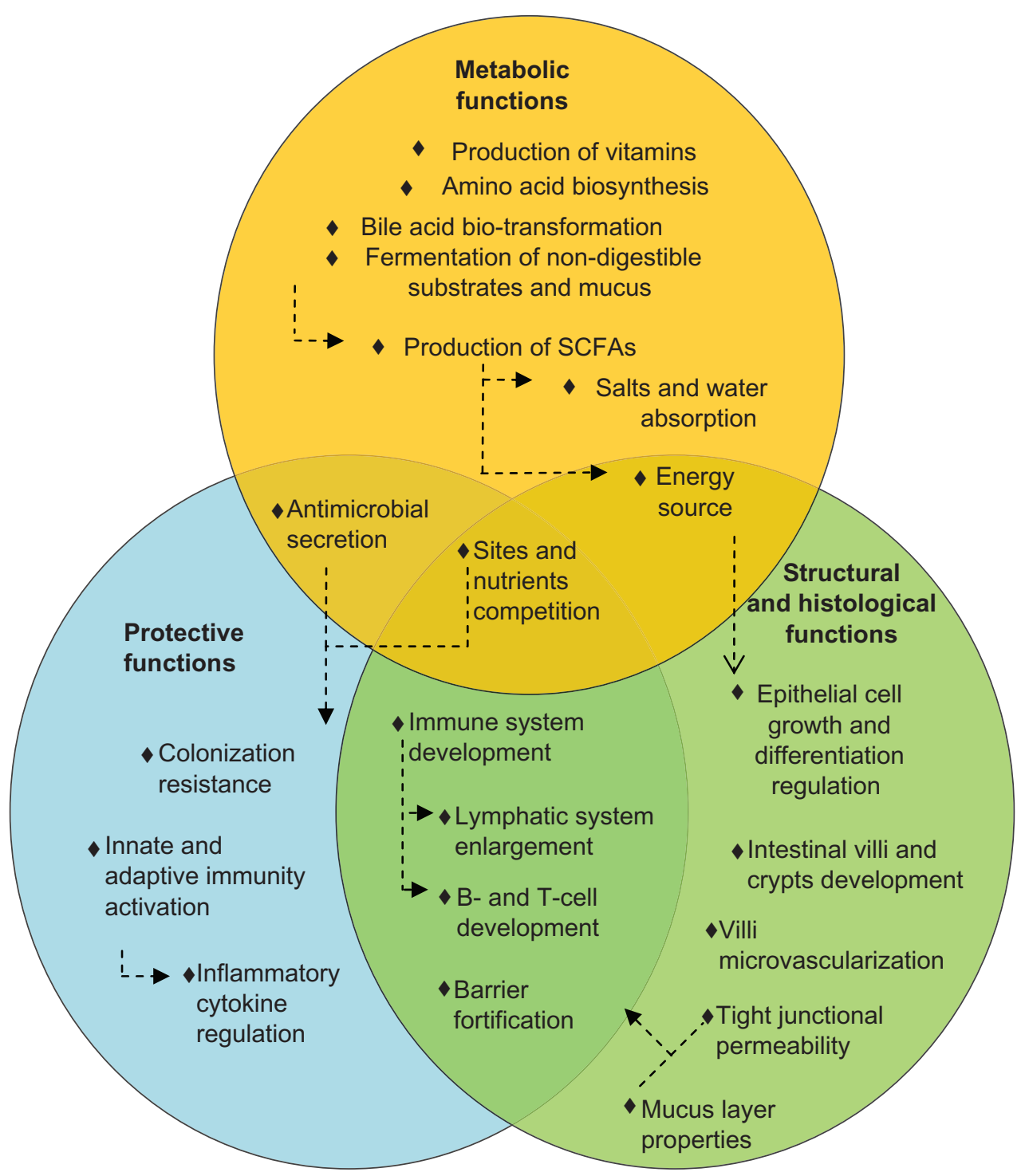

Figure I Main beneficial functions of the human gut microbiota. Circles represent the three principal classes of functions performed by the bacteria that inhabit the gut. Arrows represent causal relationships.

Abbreviation: SCFA, short chain fatty acid.

ie, protein clusters that form a barrier between the lumen and the lamina propria. Moreover, the gut microbiota is involved in cell and tissue development. Butyrate regulates cell growth and differentiation, inhibiting transformed cell growth while encouraging reversion of cells from a neoplastic to a non-neoplastic phenotype. ${ }^{31}$ The cecum villi are longer and wider, while the colonic crypts are shorter and contain fewer cells in germ-free than conventionally reared animals, possibly due to an altered rate of epithelial cell turnover or to anatomical changes arising from a reduction in bacterial count. ${ }^{32}$ Moreover, indigenous microbes shape the development of the villus microvasculature, as demonstrated in germ-free animals colonized during or after completion of postnatal gut development. ${ }^{33}$ Therefore, most of the structural and morphological development of the gut contributes to and manages the gut bacterial system (Figure 1).

\section{The bad}

Dysbiosis is a state in which the microbiota becomes altered as a consequence of an alteration in the composition of the microbiota, a change in bacterial metabolic activity, and/or a shift in local distribution of communities. Many factors can alter the gastrointestinal ecosystem, including antibiotics, psychological and physical stresses, radiation, altered peristalsis, and dietary changes..$^{34}$ At present, the focus is on the description of dysbiosis in a plethora of human disorders. 


\section{Autoimmune disease}

Autoimmune diseases occur when the body's immune system attacks and destroys healthy cells and tissues, as is the case in type 1 diabetes mellitus, celiac disease, inflammatory bowel diseases, and allergic asthma. Most often, the immune response is initiated by unknown factors. Alteration of the gut microbiota as a result of modern lifestyles is an attractive hypothesis to explain the rise in prevalence of celiac disease, type 1 diabetes mellitus, and inflammatory bowel diseases.

Celiac disease is an inflammatory disease of the small intestine that is triggered and maintained by the storage proteins of wheat, barley, and rye. Studies have investigated the composition of the microbiota in patients with celiac disease. Fecal samples from patients with celiac disease had reduced the proportions of Bifidobacterium, Clostridium histolyticum, Clostridium lituseburense, Faecalibacterium prausnitzii, and increased proportions of Bacteroides/Prevotella..$^{35}$ In addition, increased proportions of total and Gram-negative bacteria, with an increase in Bacteroides and Escherichia coli in biopsies of patients with celiac disease in the active as compared with inactive disease state and control individuals, was shown by fluorescence in situ hybridization coupled with flow cytometry. ${ }^{36}$

Type 1 diabetes mellitus, characterized by insulin deficiency resulting from immune-mediated destruction of pancreatic $\beta$ cells, is thought to be triggered by environmental factors in genetically susceptible individuals. Given that antibiotics prevented type 1 diabetes mellitus in biobreeding diabetes-prone rats and in nonobese diabetic mice, alteration of the microbiota has been associated with progression of type 1 diabetes mellitus. ${ }^{37,38}$ Moreover, evidence shows that bacterial communities from biobreeding diabetes-prone and diabetes-resistant rats differ, marked by a higher abundance of Lactobacillus and Bifidobacterium in diabetes-resistant rats. ${ }^{39}$

Inflammatory bowel diseases include ulcerative colitis and Crohn's disease. Crohn's disease is characterized by patchy and transmural inflammation that may affect any part of the gastrointestinal tract, while ulcerative colitis is a chronic episodic inflammatory condition that involves only the large bowel. ${ }^{40}$ There is evidence that species belonging to the normal gut microbiota are involved in the etiology and/or maintenance of inflammatory processes. Reduced microbial diversity, increased Bacteroidetes and Enterobacteriaceae, and decreased Firmicutes were all observed in patients with inflammatory bowel diseases. ${ }^{41}$ Another clinical study observed that Eubacterium rectale, B. fragilis, Bacteroides vulgatus, Ruminococcus albus, $R$. callidus, R. bromii, and
F. prausnitzii were 5-10-fold more abundant in healthy subjects than in patients with Crohn's disease, while Enterococcus spp, C. difficile, E. coli, Shigella flexneri, and Listeria spp were more abundant in the Crohn's disease group. ${ }^{42}$ Thus, inflammatory bowel diseases, celiac disease, and type 1 diabetes mellitus are autoimmune diseases marked by an alteration of the gut microbiota. Autoimmune regulation may be linked with the disruption of the intestinal ecosystem.

\section{Allergic disease}

The etiology of allergic diseases is ambiguous. They may be initiated and maintained by environmental factors associated with a change in gut microbiota. Correlations between allergic disease and altered fecal microbiota, antibiotic use, and dietary changes have been made. ${ }^{43-45}$ Studies of the microbiota in allergic patients have shown decreased intestinal Bifidobacteria counts, an increased prevalence of B. fragilis, and higher counts of Staphylococcus aureus and E. coli. ${ }^{46-48}$ A study reported higher levels of Bifidobacterium adolescentis and Lactobacilli Group I (Lactobacillus rhamnosus, L. paracasei, L. casei) in fecal samples of nonallergic compared with allergic children. ${ }^{43}$ Hence, it is clear that differing gut microbial communities have been observed in allergic patients. Further clinical studies are required on several age-matched groups of allergic versus control individuals classified with short age intervals.

\section{Irritable bowel syndrome}

Irritable bowel syndrome is characterized by abdominal pain, bloating, and changes in bowel habit, in the absence of any overt mucosal abnormality. Observations have directed attention towards the gut microbiota, identifying a postinfectious variant of the syndrome, ie, evidence that antibiotics induced a reduction in the microbiota which may be a risk factor, and the proposal that some patients may have bacterial overgrowth in the small bowel. ${ }^{49}$ Studies have demonstrated that patients with irritable bowel syndrome have fewer intestinal Bifidobacteria, Collinsella aerofaciens, Coprococcus eutactus, and Clostridium cocleatum, and an increase in Veillonella and Enterobacteriaeae. ${ }^{50-52}$ Thus, irritable bowel syndrome is associated with abnormal intestinal communities, but their significance in the pathogenesis of irritable bowel syndrome remains unclear.

\section{Metabolic disease}

There are genetic and environmental factors that influence obesity, with the impact of the gut microbiota being 
well documented. Research on the microbiota of obese mice establishes the link between obesity, weight gain, and intestinal dysbiosis. Findings indicate that a high-fat diet modulates the microbiota independently of obesity. ${ }^{53}$ Mice genetically predisposed to develop obesity (ob/ob) harbor more Firmicutes and fewer Bacteroidetes. ${ }^{54}$ Studies in human twins concordant for obesity have demonstrated that the fractional representation of Bacteroidetes is directly correlated with leanness. ${ }^{55}$ Moreover, microbiota transplantation from normal chow-fed ob/ob and Western diet-fed wild-type to germ-free wild-type mice caused an adiposity increase greater than that caused by transplantation from wild-type donors fed standard chow. ${ }^{56,57}$ This demonstrates a causal effect of intestinal bacteria on development of obesity. Aberrant development of the microbiota might precede obesity, because the childhood representation of Bifidobacteria and $S$. aureus has been suggested to predict the development of adulthood obesity in an inverse and direct manner. ${ }^{58}$ In light of these findings, a study was initiated which demonstrated that total short-chain fatty acids were higher in an obese group and individual short-chain fatty acid proportions shifted towards propionate in overweight subjects. ${ }^{59}$ It is assumed that gut dysbiosis may contribute to the development of obesity.

Type 2 diabetes is characterized by defects in insulin secretion and action. Research has characterized the fecal microbiota composition of adults with type 2 diabetes and showed reduced proportions of Firmicutes and Clostridia. ${ }^{60}$ The ratios of Bacteroidetes to Firmicutes, as well as Bacteroides/Prevotella to Clostridium coccoides and E. rectale groups correlated positively with plasma glucose concentration. Similarly, class $\beta$-Proteobacteria was highly enriched in diabetic individuals and positively correlated with plasma glucose. Other authors have demonstrated that Prevotella was associated with healthy groups, while Bacteroides and Parabacteroides were prevalent in diabetic patients, who also had fewer counts of fecal B. vulgatus and Bifidobacteria. ${ }^{61}$ The evidence demonstrates that metabolic diseases are associated with a shift in the balance of the microbiota. Confirmation of gut dysbiosis in type 2 diabetes patients requires additional clinical trials.

\section{Alcoholic liver disease}

Alcoholic liver disease, arising from excessive ingestion of alcohol, is the primary cause of liver failure in the Western world. It has been demonstrated in one study that daily alcohol consumption affects composition of the colonic microbiota. ${ }^{62}$ The authors pointed to a specific fingerprint of dysbiotic microbiota which could potentially identify susceptible heavy drinkers at high risk for alcoholic liver disease. Further examination is required to support fully the link between gut dysbiosis and alcoholic liver disease.

\section{Bacterial infection}

It is well established that a disruption in the commensal microbiota increases susceptibility to enteric infections. Antibiotic-treated mice are particularly useful for studying colitis induced by Salmonella spp, Shigella spp, and E. coli infections. In addition, in murine Citrobacter rodentium infections, pathogen colonization is associated with a reduced total density and a relative increase in $\gamma$-Proteobacteria. ${ }^{63}$ Furthermore, elderly patients with $C$. difficile-associated diarrhea demonstrate reduced numbers of Bacteroides, Prevotella, and Bifidobacteria, and a greater diversity of facultative species, ie, Lactobacilli and Clostridia. ${ }^{64}$ The evidence suggests an association between disruption of the gut microbiota and bacterial infections, further accentuating the dysbiosis.

\section{Colorectal cancer}

Colorectal cancer is a disease of the Western world, with the most common type being adenocarcinomas which develop from glandular cells lining the wall of the bowel. ${ }^{65}$ Genetic and induced models of intestinal neoplasia have shown that, under germ-free conditions, colitis and tumor formation are reduced compared with monoassociated and conventional animals. ${ }^{66-68}$ In addition, in vivo colonization of enterotoxigenic $B$. fragilis a human colonic commensal bacteria, has been linked to the development of colorectal cancer. ${ }^{69}$ Furthermore, colorectal cancer patients demonstrate decreased levels of $E$. rectale and $F$. prausnitzii compared with healthy volunteers, and increased populations of E. faecalis. ${ }^{70}$ Recently, a clinical trial showed that patients with colorectal cancer had significant elevation of the Bacteroides-Prevotella population..$^{71}$ Therefore, studies that have examined the gut microbiota in colorectal cancer have reported an association between microbiota and pathogenesis of colorectal cancer. The abnormal profile of bacterial communities, activities, and metabolites in human disease is summarized in Table 3.

\section{The ugly}

Altered composition of the human gastrointestinal ecosystem can lead to physiological changes in the intestinal environment, disrupting the functions of the microbiota and having serious consequences for human health. 
Table 3 Imbalances of human gastrointestinal bacterial communities in human disease

\begin{tabular}{lll}
\hline $\begin{array}{l}\text { Imbalance of human gastrointestinal bacterial communities } \\
\text { Specific overabundance }\end{array}$ & \\
$\begin{array}{l}\text { Specific shortage } \\
\text { Health status }\end{array}$ & Decrease in \\
\hline Increase in & Celiac disease & Gram-positive Bifidobacteria, Clostridium histolyticum \\
\hline Gram negative, Bacteroides-Prevotella, & Inflammatory bowel diseases & and C. liteseburense, Faecalibacterium prausnitzii \\
Escherichia coli & & Firmicutes, Eubacterium rectale, Bacteroides fragilis, \\
Enterobacteriaceae, Bacteroidetes, Enterococci, & B. vulgatus, Ruminococcus albus, R. callidus, R. bromii, \\
Clostridium difficile, E. coli, Shigella flexneri, and & and F. prausnitzii \\
Listeria spp & Irritable bowel syndrome & Bifidobacteria, Collinsella aerofaciens, Coprococcus \\
Veillonella, Enterobacteriaceae & eutactus, Clostridium cocleatum \\
Staphylococcus aureus, E. coli, Bifidobacterium & Allergic diseases & Bifidobacteria \\
adolescentis, Lactobacilli, B. fragilis & Obesity & Bacteroidetes, Bifidobacteria, Staphylococcus aureus \\
Firmicutes & Type 2 diabetes & Firmicutes, Clostridia, Bifidobacteria, Bacteroides \\
B-Proteobacteria, Bacteroides, Parabacteroides & vulgatus \\
Bacteroides, Prevotella, Enterococcus faecalis. & Colorectal cancer & E. rectale and F. prausnitzii.
\end{tabular}

Note: Each bacteria group has been shown to be related to the disease, independently of one another.

\section{Altered gut microbiota may trigger serious immune deregulation}

The hygiene hypothesis predicts that increased hygiene, use of antibiotics, and sterile food preparation result in isolation of the immune system from positive microbial exposure, favoring susceptibility to immune-mediated disorders. ${ }^{72}$ Epidemiological studies have linked a decreasing burden of infection with a rising incidence of immunological disorders. ${ }^{73,74}$ The presence of environmental viral agents are also associated with the incidence of spontaneous type 1 diabetes. ${ }^{75}$ Furthermore, the microbiota of nonobese diabetic mice deficient for the myeloid differentiation primary response gene 88 (MyD88) signaling molecule protects mice against developing diabetes. ${ }^{76}$ Inactivation of MyD88 leads to gut dysbiosis, further inhibiting the autoimmunity occurring

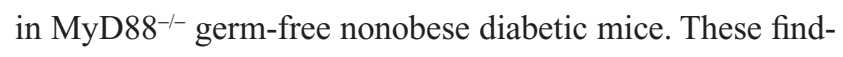
ings support a causal inverse relationship between microbial exposure and immunological disorders.

There are several underlying mechanisms of the hygiene hypothesis, ie: lack of microbial burden in childhood, predisposing the host to allergic disorders due to a Thelper type 1/ type 2 deviation; defective maturation of regulatory $\mathrm{T}$ cells as a consequence of modern lifestyles; antigenic competition from infectious agents inhibiting responses to weak antigens; protection from allergic diseases through mechanisms independent of their constitutive antigens, leading to stimulation of nonantigen-specific receptors; and development of an aggressive immune response caused by genetic hyperimmunoreactivity triggered by dysbiosis. ${ }^{72}$ Therefore, the disruption of cross-talk between the commensal microbiota and the immune system, as a result of modern lifestyles, may lead to development of allergic, autoimmune, and autoimmuneassociated diseases (Figure 2A).

\section{Specific gut dysbiosis can engender metabolic endotoxemia}

Obesity and type 2 diabetes are associated with chronic lowgrade inflammation and endotoxemia. Lipopolysaccharide administration and a high-fat diet lead to an increase in adipose tissue, impaired glucose tolerance, and insulin resistance, while dietary modulation reverses this phenotype. ${ }^{77,78} \mathrm{Chronic}$

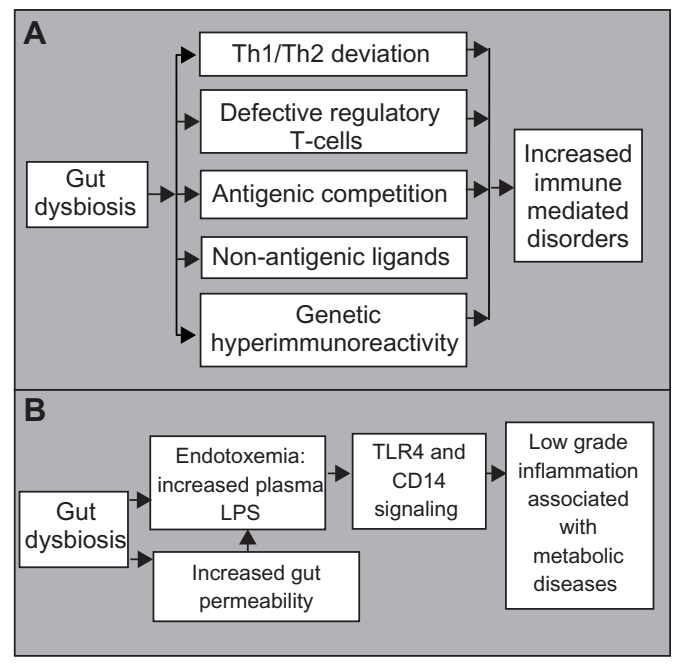

Figure 2 Proposed mechanisms whereby an altered microbial balance in the gut can lead to $\mathbf{A}$ ) an increase in immune mediated disorders and $\mathbf{B}$ ) chronic low-grade inflammation.

Abbreviations: Th, T helper type; CDI4, cluster of differentiation 14; LPS, lipopolysaccharide; TLR4, toll-like receptor 4. 
inflammation, elicited by endotoxemia, may cause activation of the immune system. The importance of gut-derived endotoxins in alcoholic liver disease has also been supported. ${ }^{79}$ Circulating endotoxin levels were increased in mice and rats following chronic alcohol ingestion, while antibiotic treatment provided protection from alcoholic liver disease. In addition, plasma endotoxins were augmented in patients with alcoholic liver disease. The evidence also suggests that endotoxins contribute to the pathogenesis of nonalcoholic fatty liver disease, considered to be a hepatic manifestation of metabolic syndrome and obesity. Indeed, plasma endotoxins are higher in patients with nonalcoholic fatty liver disease and are associated with intestinal overgrowth and induction of hepatic toll-like receptor $4 .^{80,81}$ Gut permeability, which influences the systemic distribution of endotoxins, may further induce metabolic endotoxemia. Mice fed a high-fat diet demonstrate increased gut permeability and metabolic endotoxemia, associated with disruption of tight junction proteins. ${ }^{82}$ Furthermore, an increase in Bifidobacteria induced by nutritional supplements is correlated with an improved gut barrier, lower portal lipopolysaccharide levels, and lower inflammatory tone in ob/ob mice. ${ }^{83}$ Taken together, we suggest that gut dysbiosis, characterized by decreased Bifidobacteria and increased lipopolysaccharide release, disrupts the epithelial barrier, resulting in a leaky gut and leading to colonic and systemic inflammation which contributes to alcoholic liver disease, nonalcoholic fatty liver disease, obesity, and type 2 diabetes (Figure 2B). It remains unclear which Gram-negative bacteria are responsible for the increase in lipopolysaccharide.

\section{Bacterial infection might be promoted by gut dysbiosis}

Pathogenic bacteria can invade the gastrointestinal tract and infect the body, producing sepsis, shock, multisystem organ failure, and death of the host. The mechanisms by which pathogens overcome obstacles to achieve successful infection are uncertain. Pathogenic infections might be facilitated by disruption of the intestinal ecosystem by environmental factors. A mechanism based on the triggering of the host's immune defenses was elucidated using models of $C$. rodentium (mimicking diarrheal pathogenassociated inflammation), Campylobacter jejuni infection, and chemically and genetically induced models of intestinal inflammation are used for altered microbiota investigations. ${ }^{63}$ An overgrowth of Enterobacteriaceae was observed in all models, indicating that inflammationinduced microbiota changes support colonization by aerotolerant bacteria. The inflammatory response, triggered by the invading pathogen, may function to enhance its colonization, further facilitating its virulence. Thus, alteration of the gut microbiota, initiated by host and environmental factors, may participate in the initiation of diseases caused by infectious agent (Figure 3A).

\section{Abnormal bacterial metabolite levels may trigger cancer}

Many etiological bacterial mechanisms have been hypothesized to promote carcinogenesis. Amongst those, hydrogen sulfide, a product of bacterial sulfate reduction, appears to be linked to the incidence of chronic disorders, such as ulcerative colitis and colorectal cancer. Because DNA strand breaks are associated with mutation and promotion of carcinogenesis, bacterial hydrogen sulfide may be responsible for the induction of mutations in the development of sporadic colorectal cancer. ${ }^{84}$ Reactive oxygen intermediates also cause DNA damage, and their numbers are higher in chronic inflammation and colorectal cancer, as observed in the fecal matrix. ${ }^{85}$ In addition, hydrophobic bile acids have been shown to promote colorectal carcinogenesis by inducing micronuclei formation, mitotic perturbations, and decreases in spindle checkpoint proteins. ${ }^{86}$ Intestinal bacteria may also function as promoters of carcinogenesis by increasing the progression of chemically induced aberrant crypt foci. ${ }^{87,88}$ Therefore, despite limited studies on the occurrence of gut dysbiosis and tumorigenesis, we bring to a close the mechanisms that support the implication of detrimental intestinal bacteria in promoting carcinogenesis (Figure 3B).

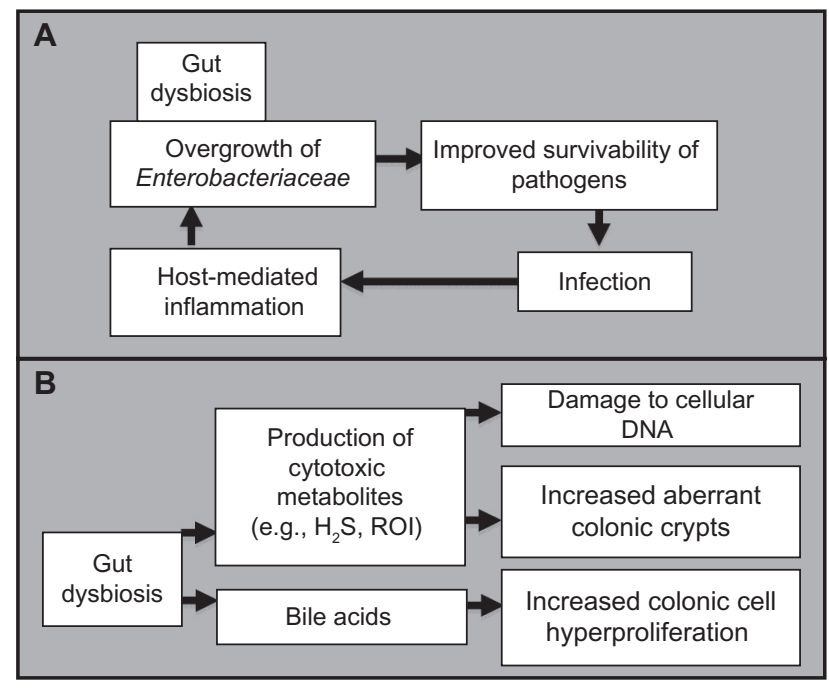

Figure 3 Proposed mechanism whereby an altered microbial balance in the gut can A) be driven by foreign pathogenic invasion and further increase the likelihood of future infections, and B) lead to the promotion of carcinogenesis.

Abbreviations: $\mathrm{H}_{2} \mathrm{~S}$, hydrogen sulfide; ROI, reactive oxygen intermediate. 


\section{Gut microbiota alters energy and lipid metabolism}

Gordon et al investigated the influence of microbiota on fat and lipid metabolism, demonstrating that reared mice have more body and gonadal fat than germ-free mice, despite reduced chow consumption. The increase in fat was accompanied with increased fasting glucose and insulin levels and an insulin-resistant state. ${ }^{89}$ Transplantation of the microbiota from ob/ob mice to germ-free mice resulted in a greater increase in body fat than from lean donors. ${ }^{56}$ Two mechanisms are suggested. First, colonization of the gut may suppress expression of fasting-induced adipose factor, increasing the activity of lipoprotein lipase, leading to an increased uptake of fatty acids and triglyceride storage. The second mechanism is based on the processing of dietary polysaccharides by bacteria that may increase hepatic lipogenesis through expression of sterol response element binding protein 1 and carbohydrate response element binding protein. Other authors suggest that the complex formed by short-chain fatty acids and $\mathrm{G}$ protein-coupled receptor 41 may increase circulating levels of peptide YY, which may further increase energy extraction from the diet. ${ }^{90}$ It was also demonstrated that in the absence of gut microbiota, AMP-activated protein kinase activity is constitutively higher in muscle, leading to higher phosphorylation of its specific target, acetyl CoA carboxylase, promoting mitochondrial fatty acid oxidation. ${ }^{91}$ Finally, the microbiota may affect insulin resistance and steatosis by regulating choline metabolism. ${ }^{92}$ Thus, alteration of the gut microbiota causes defective energy and lipid metabolism leading to the development of metabolic disease (Figure 4).

\section{Alter the gut microbiota to favor human health}

The relationship between health and the gastrointestinal system is established. Due to the inherent plasticity of microbiota, one can consider exploiting it to develop biotherapeutics.

\section{Probiotics}

Probiotics are "live microorganisms, which, when administered in adequate amounts, confer a health benefit on the host". ${ }^{93}$ Probiotics have been shown to have effects on irritable bowel diseases, metabolic syndromes, enterocolitis, immunomodulation, pathogen defense, and urogenital infections. ${ }^{94-96}$ Mechanisms of probiotics include remodeling of microbial communities and suppression of pathogens, suppression of proinflammatory factors, effects on epithelial cell differentiation, and proliferation and promotion of the intestinal barrier. ${ }^{97}$

\section{Microencapsulation and other methods for targeted delivery}

Microencapsulation, which provides living cells with a physical protection barrier, is primarily used to improve probiotic activity during gastrointestinal transit, while allowing the diffusion of metabolites and substrates into and out of the capsule. Secondly, it offers a bacterial delivery system targeted to a specific part of the gastrointestinal tract. Thirdly, microencapsulation ensures immunomodulation by preventing interaction between the host immune system and entrapped probiotic bacterial cells. ${ }^{98,99}$ In addition, there are other excellent formulations available for delivery of probiotic cells to achieve optimal clinical benefits.

\section{Prebiotics}

Prebiotics are "nondigestible food ingredients that beneficially affect the host by selectively stimulating the growth and/or the activity of one or a limited number of bacteria in the colon, and thus improves host health". ${ }^{100}$ A prebiotic should not be hydrolyzed by human intestinal enzymes, but selectively fermented by bacteria, benefiting the host. Effects of prebiotic administration include reduced triglyceride levels, improved postprandial glucose levels, and reduced intestinal permeability and inflammation. ${ }^{100-102}$ In addition to prebiotics, known foods and drugs are also being developed to enhance the growth of health-promoting bacterial cell populations in the gastrointestinal tract, with the aim of preventing or treating a number of diseases.

\section{Symbiotic association of probiotics and prebiotics}

It has been hypothesized that in combining probiotics and prebiotics, one would not only achieve the combined effects of the two components, but also a synergistic effect. This is the principle on which symbiotics are based. ${ }^{103}$

\section{Antibiotics combined with probiotics}

The evidence suggests that probiotic bacteria suppress gastrointestinal pathogens and potentiate antibiotic efficacy by production of antibacterial factors, including bacteriocins. ${ }^{97}$ With the use of antibiotic drugs, bacterial overgrowth can be controlled, and translocation in specific conditions of increased risk can be prevented. ${ }^{83}$ In brief, strong evidence is available that probiotics, prebiotics, and antibiotics can successfully exploit the natural microbial composition of 


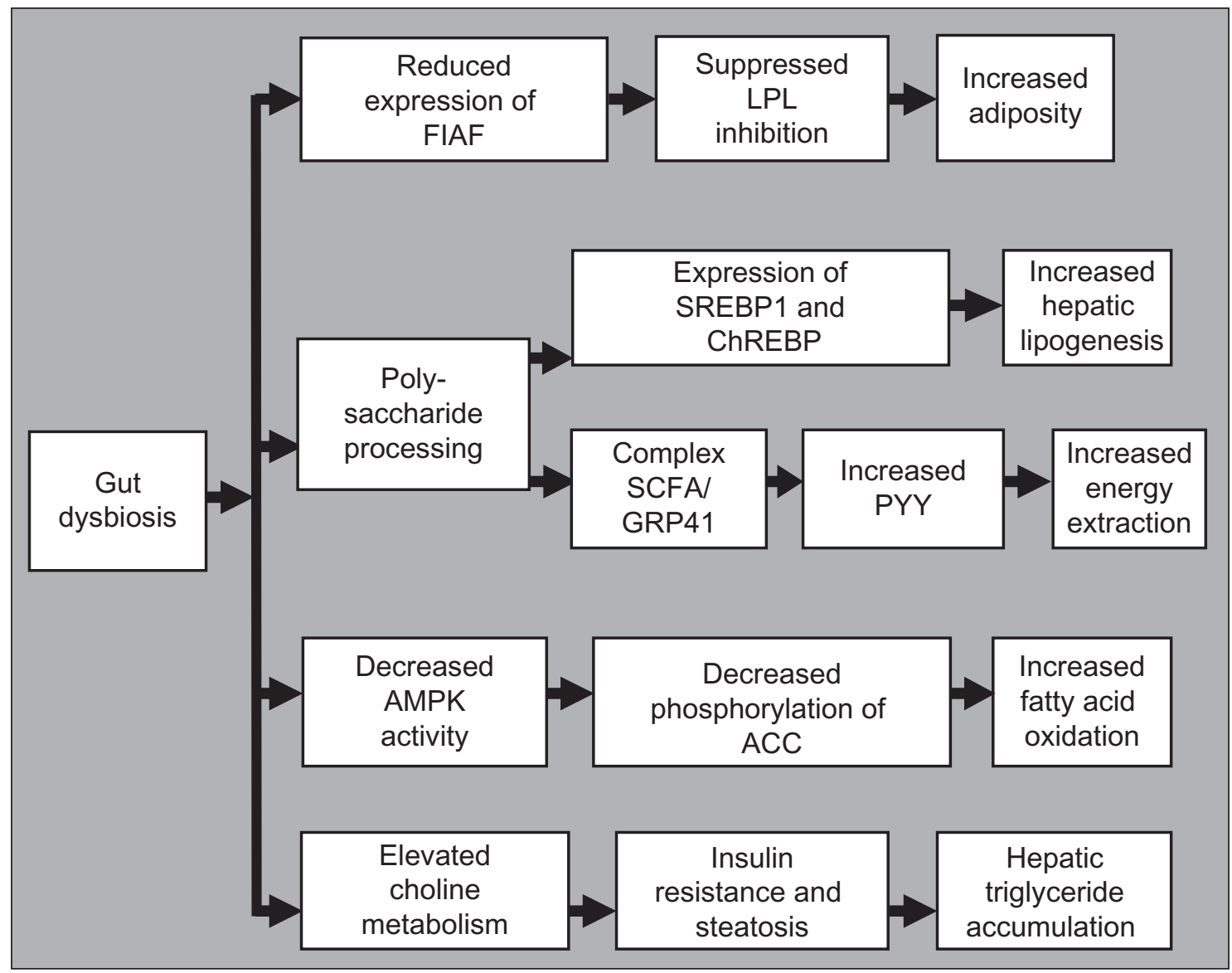

Figure 4 Proposed mechanisms by which an altered balance of the gut microbiota can lead to dysfunctional energy and lipid metabolism.

Abbreviations: AMPK, AMP-activated protein kinase; ChREBP, carbohydrate regulatory element binding protein; FIAF, fasting-induced adipose factor; GPR4I, G proteincoupled receptor 4I; LPL, lipoprotein lipase; PYY, protein YY; SCFA, short-chain fatty acid; SREBPI, sterol regulatory element binding protein I.

the gut to treat and/or prevent diseases for improving human health and well being.

\section{Future directions}

Advances in exploring and modeling the microbiota are generating a wealth of knowledge about human health and disease, and contributing to the development of new biotherapeutics. Significant advances have been made in the selection and characterization of specific probiotic cultures and/or prebiotics and subsequent substantiation of health claims relating to their consumption. However, there is still much skepticism in the medical community with respect to the effects demonstrated. Firstly, the disease model used affects the results significantly. Secondly, there is a lack of large, controlled, randomized human trials supporting the beneficial claims. Thirdly, the harsh conditions of the gastrointestinal tract can impede the delivery of probiotic bacterial cells. One significant advantage of using prebiotics as opposed to probiotics is that they overcome the viability issue. Prebiotics are, by definition, not hydrolyzed by enzymes during gastrointestinal transit and, therefore end up being available to stimulate selective growth of gut microbiota. Nevertheless, it is hardly possible to demonstrate the selectivity criterion of prebiotics. On the contrary, microencapsulation of probiotic bacteria is a delivery method that overcomes the viability issue and is also selective.

Therefore, it is easy to envisage that microencapsulated probiotics may soon be available on the market, and research in the long term may focus on developing formulations combining microencapsulated probiotics, prebiotics and/or antibiotics. The main challenge is developing suitable models to characterize and understand the microbiota, and developing effective treatment formulations, such as targeted delivery of probiotics within the gastrointestinal tract.

\section{Towards new models of human gut microbiota}

In vitro models of the human microbiota are essential to screen, characterize, develop, and perform mechanistic studies under controlled parameters. To test the therapies 
being developed effectively, special attention has to be directed to the development and optimization of in vitro models of the microbiota, given that these are rare. Models to mimic the whole gastrointestinal tract and specific compartments are essential. The challenge is to create a fermentation system featuring microbial diversity similar to that in the human gastrointestinal tract. Due to sampling complications, the microbiota of a fecal inoculum is assumed to be representative of the intestinal microbiota. ${ }^{104}$ The computer-controlled dynamic human gastrointestinal model consists of a succession of five vessels: the stomach, the small intestine, and the ascending, transverse, and descending colon (Figures 5A and 5B). ${ }^{105,106}$ Temperature, $\mathrm{pH}$, and anaerobic parameters are all controlled using Labview $^{\circledR}$ software. The system is equipped with portholes for the addition of medium, the removal of spent culture, and the administration of therapeutics. Attention is also needed to simulate the bacterial microhabitat of the intestines, because the metabolism and functioning of the mucosalassociated microbiota differ from those free-living in the lumen. ${ }^{106}$ Efforts should be made to understand the effect of gastrointestinal tract adhesion of bacterial cells on bacterial metabolism by designing a model to investigate adhesion of probiotics for gut microbiota modulation.

\section{Microencapsulation to boost efficacy of probiotic treatment}

There are many methods for microencapsulation of bacterial cells available, and these can be effectively used in boosting probiotic oral delivery and clinical efficacy. Our research interest is mainly focused on the customization of a myriad of microencapsulated probiotic formulations

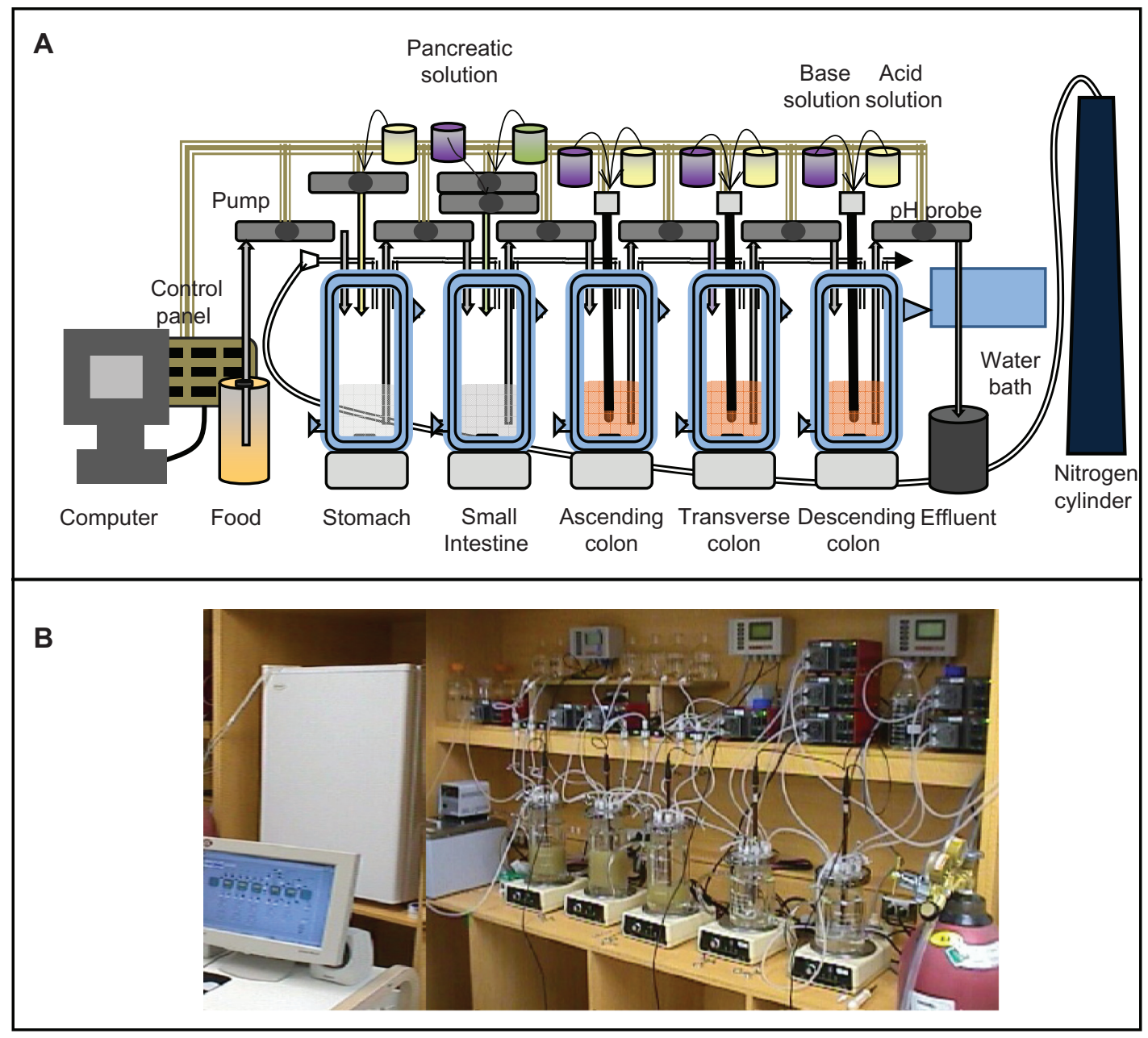

Figure 5 Computer-controlled dynamic human gastrointestinal (GI) model used for studies on the human gut microbiota. A) Schematic representation, B) photograph. Vessels in series representing stomach, small intestine, ascending colon, transverse colon, and descending colon. All vessels can be continuously magnetically stirred; temperature can be controlled by the flow of hot water in the double jacketed vessel. Food can be given at a time interval and samples can be collected from any Gl part at any time (eg, spent removal of the spent culture at defined intervals). This also allows for the administration of biotherapeutics, control of pH, enzyme, anerobic atmosphere and other Gl parameters effecting gut microbiota.. 
using polyelectrolyte complexation, a widely used technique based on the interaction of oppositely charged polymers that form a physical membrane around the probiotic. ${ }^{99,105-111}$ The physicochemical properties of the capsules are engineered to guarantee survival of the bacteria, appropriate diffusion of metabolites and substrates, and targeted delivery. In gastrointestinal tract simulators, the enzymatic activity, stability, and viability of microencapsulated probiotics have been demonstrated. ${ }^{105-109}$ Results confirm the potential of orally delivered microencapsulated bacteria to manage hypercholesterolemia, hypertriglyceridemia, and colon cancer. ${ }^{108,111}$ For microencapsulated probiotics to be marketable, research must be directed at developing structural and functional models of the microbiota to test the therapeutic formulations. Finally, in vivo models should evaluate the efficacy of microencapsulated probiotic formulations while characterizing preclinical cellular and tissue responses. The potential of microencapsulated Lactobacillus fermentum to lower cholesterol and triglycerides in Bio F(1)B hamsters fed a hypercholesterolemic diet was investigated. ${ }^{108}$ Treatment with the bacterial formulation reduced total cholesterol, low-density lipoprotein cholesterol, and triglycerides, and also reduced the progression of atherosclerotic lesions. The antitumorigenic properties of microencapsulated probiotics in multiple intestinal neoplasia were also investigated in mice carrying a germline APC mutation. ${ }^{111}$ Oral administration of microencapsulated Lactobacillus acidophilus resulted in suppression of colon tumor incidence, multiplicity, and size. Preclinical trials confirm the potential of orally delivered microencapsulated probiotics for managing hypercholesterolemia, hypertriglyceridemia, and colon cancer.

\section{Conclusion}

This is an extensive and timely review of the gut microbiota and its role in human health and disease. First described are the key players among the microbiota, how they develop into a network in the gastrointestinal tract, their roles in various gastrointestinal and other diseases, methods to study human gut microbiota, and associated health benefits and limitations. Interest in the microbiota arose after the realization that an altered balance in the gut could lead to disease. By using probiotics, prebiotics, and antibiotics, one can tune the composition of the gut to improve the health of the host. Optimization of methods to modulate and characterize the microbiota and probiotics still remains to be done. The microbiota itself can allow for the analysis of health, and biomarkers of a given microbiota can be indicative of disease.
Although preliminary, two animal models have shown that microbial metabolism is correlated with specific patterns of metabolites excreted in urine. ${ }^{112}$ This could potentially be a significant breakthrough in the new realm of personalized medicine.

Gut microbiota is an area of research with potential for pure scientific exploration with significant biotherapeutic applications. It remains largely unexplored. This is due to the complexity of the microbiota and the difficulties in collection and analysis of data. In addition, lack of understanding of the role of bacterial cells in human health and lack of well defined clinical trials on known beneficial probiotics, other bacterial cells, and associated systems, such as delivery systems, are seriously hampering this very important area of biological therapy. Development of cutting-edge technologies for understanding human gut microbiota, their manipulations, and screening and development of cutting edge formulations for probiotic delivery, such as microencapsulation, are strongly needed, along with accurate in vitro models.

\section{Highlights}

The human gut microbiota is an asset for human homeostasis.

- The human gut microbiota, which resides within the gastrointestinal tract system, is composed of trillions of microorganisms with tremendous diversity and complexity

- The gut microbiota should be considered as a vital organ, carrying essential metabolic, protective, and structural/ histological functions in maintaining body homeostasis, human health and other manifestations

- An altered composition of the intestinal ecosystem, a state called gut dysbiosis, can lead to physiological changes in the intestinal environment, disrupting the functions of the gut microbiota, autoimmune, allergic, metabolic and alcoholic liver diseases, irritable bowel syndrome, colorectal cancer, and bacterial infections have all been linked to gut dysbiosis

- Bacterial imbalances can be responsible for immunological deregulation, breakdown of colonization resistance, induction of systemic endotoxemia, production of carcinogenic compounds and alteration of energy and lipid metabolism

- Due to the inherent plasticity of the gut microbiota, therapeutics such as probiotics, prebiotics, and antibiotics are used to modulate the human intestinal ecosystem to obtain better human health 
- Major efforts should be directed towards development of in vitro and in vivo models to understand the human gut microbiota and explore development of biotherapeutic possibilities and methods, such as microencapsulation, for suitable delivery of beneficial bacterial cells to the gastrointestinal tract and other systems for human health.

\section{Acknowledgment}

This work is supported by the Canadian Institutes of Health Research, research operating grant MOP-64308 (to SP), the Natural Sciences and Engineering Research Council of Canada (to CTD), the Fonds Québécois de la Recherche sur la Nature et les Technologies (to MCC), and Micropharma Limited (to SP).

\section{Disclosure}

The authors report no conflicts of interest in this work.

\section{References}

1. Savage DC. Microbial ecology of the gastrointestinal tract. Annu Rev Microbiol. 1977;31:107-133.

2. Qin J, Li R, Raes J, et al. A human gut microbial gene catalogue established by metagenomic sequencing. Nature. 2010;464:59-65.

3. Backhed F, Ley RE, Sonnenburg JL, Peterson DA, Gordon JI. Host-bacterial mutualism in the human intestine. Science. 2005;307: 1915-1920.

4. McConnell EL, Fadda HM, Basit AW. Gut instincts: Explorations in intestinal physiology and drug delivery. Int J Pharm. 2008;364: 213-226.

5. Mshvildadze M, Neu J. The infant intestinal microbiome: Friend or foe? Early Hum Dev. 2010;86 Suppl 1:67-71.

6. Adlerberth I, Wold AE. Establishment of the gut microbiota in Western infants. Acta Paediatr. 2009;98:229-238.

7. Rumney CJ, Rowland IR. In vivo and in vitro models of the human colonic flora. Crit Rev Food Sci Nutr. 1992;31:299-331.

8. Sekirov I, Russell SL, Antunes LC, Finlay BB. Gut microbiota in health and disease. Physiol Rev. 2010;90:859-904.

9. Dethlefsen L, Eckburg PB, Bik EM, Relman DA. Assembly of the human intestinal microbiota. Trends Ecol Evol. 2006;21: 517-523.

10. Blaut M, Collins MD, Welling GW, Dore J, Van LJ, de Vos W. Molecular biological methods for studying the gut microbiota: The EU human gut flora project. Br J Nutr. 2002;87 Suppl 2:S203-211.

11. McCartney AL. Application of molecular biological methods for studying probiotics and the gut flora. Br J Nutr. 2002;88 Suppl 1:S29-S37.

12. Peter H, Sommaruga R. An evaluation of methods to study the gut bacterial community composition of freshwater zooplankton. J Plankton Res. 2008;30:997-1006.

13. Lefebvre P, Cariou B, Lien F, Kuipers F, Staels B. Role of bile acids and bile acid receptors in metabolic regulation. Physiol Rev. 2009;89:147-191.

14. Wong JM, de SR, Kendall CW, Emam A, Jenkins DJ. Colonic health: Fermentation and short chain fatty acids. J Clin Gastroenterol. 2006;40:235-243.

15. Chen WJ, Anderson JW, Jennings D. Propionate may mediate the hypocholesterolemic effects of certain soluble plant fibers in cholesterol-fed rats. Proc Soc Exp Biol Med. 1984;175:215-218.

16. Berggren AM, Nyman EM, Lundquist I, Bjorck IM. Influence of orally and rectally administered propionate on cholesterol and glucose metabolism in obese rats. Br J Nutr. 1996;76:287-294.
17. Tlaskalova-Hogenova H, Stepankova R, Hudcovic T, et al. Commensal bacteria (normal microflora), mucosal immunity and chronic inflammatory and autoimmune diseases. Immunol Lett. 2004;93:97-108.

18. Round JL, Mazmanian SK. The gut microbiota shapes intestinal immune responses during health and disease. Nat Rev Immunol. 2009;9: 313-323.

19. Cebra JJ, Periwal SB, Lee G, Lee F, Shroff KE. Development and maintenance of the gut-associated lymphoid tissue (GALT): The roles of enteric bacteria and viruses. Dev Immunol. 1998;6:13-18.

20. Bouskra D, Brezillon C, Berard M, et al. Lymphoid tissue genesis induced by commensals through NOD1 regulates intestinal homeostasis. Nature. 2008;456:507-510.

21. Haverson K, Rehakova Z, Sinkora J, Sver L, Bailey M. Immune development in jejunal mucosa after colonization with selected commensal gut bacteria: A study in germ-free pigs. Vet Immunol Immunopathol. 2007;119:243-253.

22. Hapfelmeier S, Lawson MA, Slack E, et al. Reversible microbial colonization of germ-free mice reveals the dynamics of IgA immune responses. Science. 2010;328:1705-1709.

23. Atarashi K, Tanoue T, Shima T, et al. Induction of colonic regulatory T cells by indigenous Clostridium species. Science. 2011;331:337-341.

24. Mazmanian SK, Liu CH, Tzianabos AO, Kasper DL. An immunomodulatory molecule of symbiotic bacteria directs maturation of the host immune system. Cell. 2005;122:107-118.

25. Ivanov II, Atarashi K, Manel N, et al. Induction of intestinal Th17 cells by segmented filamentous bacteria. Cell. 2009;139:485-498.

26. Mazmanian SK, Round JL, Kasper DL. A microbial symbiosis factor prevents intestinal inflammatory disease. Nature. 2008;453: $620-625$.

27. Luhrs H, Gerke T, Muller JG, et al. Butyrate inhibits NF-kappaB activation in lamina propria macrophages of patients with ulcerative colitis. Scand J Gastroenterol. 2002;37:458-466.

28. Maslowski KM, Vieira AT, Ng A, et al. Regulation of inflammatory responses by gut microbiota and chemoattractant receptor GPR43. Nature. 2009;461:1282-1286.

29. Kleessen B, Blaut M. Modulation of gut mucosal biofilms. Br J Nutr. 2005;93 Suppl 1:S35-S40.

30. Hamer HM, Jonkers D, Venema K, Vanhoutvin S, Troost FJ, Brummer RJ. Review article: The role of butyrate on colonic function. Aliment Pharmacol Ther. 2008;27:104-119.

31. Salminen S, Bouley C, Boutron-Ruault MC, et al. Functional food science and gastrointestinal physiology and function. Br J Nutr. 1998;80 Suppl 1:S147-S171.

32. Hill DA, Artis D. Intestinal bacteria and the regulation of immune cell homeostasis. Annu Rev Immunol. 2010;28:623-667.

33. Stappenbeck TS, Hooper LV, Gordon JI. Developmental regulation of intestinal angiogenesis by indigenous microbes via Paneth cells. Proc Natl Acad Sci U S A. 2002;99:15451-15455.

34. Hawrelak JA, Myers SP. The causes of intestinal dysbiosis: A review. Altern Med Rev. 2004;9:180-197.

35. De PG, Nadal I, Medina M, et al. Intestinal dysbiosis and reduced immunoglobulin-coated bacteria associated with coeliac disease in children. BMC Microbiol. 2010;10:63.

36. Nadal I, Donat E, Ribes-Koninckx C, Calabuig M, Sanz Y. Imbalance in the composition of the duodenal microbiota of children with coeliac disease. J Med Microbiol. 2007;56:1669-1674.

37. Brugman S, Klatter FA, Visser JT, et al. Antibiotic treatment partially protects against type 1 diabetes in the bio-breeding diabetes-prone rat. Is the gut flora involved in the development of type 1 diabetes? Diabetologia. 2006;49:2105-2108.

38. Schwartz RF, Neu J, Schatz D, Atkinson MA, Wasserfall C. Antibiotic treatment partially protects against type 1 diabetes in the bio-breeding diabetes-prone rat. Is the gut flora involved in the development of type 1 diabetes? Diabetologia. 2007;50:220-221.

39. Roesch LF, Lorca GL, Casella G, et al. Culture-independent identification of gut bacteria correlated with the onset of diabetes in a rat model. ISME J. 2009;3:536-548. 
40. MacFarlane S, Steed H, MacFarlane GT. Intestinal bacteria and inflammatory bowel disease. Crit Rev Clin Lab Sci. 2009;46:25-54.

41. Walker AW, Sanderson JD, Churcher C, et al. High-throughput clone library analysis of the mucosa-associated microbiota reveals dysbiosis and differences between inflamed and non-inflamed regions of the intestine in inflammatory bowel disease. BMC Microbiol. 2011;11:7.

42. Kang S, Denman SE, Morrison M, et al. Dysbiosis of fecal microbiota in Crohn's disease patients as revealed by a custom phylogenetic microarray. Inflamm Bowel Dis. 2010;16:2034-2042.

43. Sjogren YM, Jenmalm MC, Bottcher MF, Bjorksten B, SverremarkEkstrom E. Altered early infant gut microbiota in children developing allergy up to 5 years of age. Clin Exp Allergy. 2009;39:518-526.

44. Watanabe J, Fujiwara R, Sasajima N, Ito S, Sonoyama K. Administration of antibiotics during infancy promoted the development of atopic dermatitis-like skin lesions in NC/Nga mice. Biosci Biotechnol Biochem. 2010;74:358-363.

45. Gruber C, van Stuijvenberg M, Mosca F, et al. Reduced occurrence of early atopic dermatitis because of immunoactive prebiotics among low-atopy-risk infants. J Allergy Clin Immunol. 2010;126:791-797.

46. Penders J, Stobberingh EE, Thijs C, et al. Molecular fingerprinting of the intestinal microbiota of infants in whom atopic eczema was or was not developing. Clin Exp Allergy. 2006;36:1602-1608.

47. Vael C, Nelen V, Verhulst SL, Goossens H, Desager KN. Early intestinal Bacteroides fragilis colonisation and development of asthma. BMC Pulm Med. 2008;8:19.

48. Watanabe S, Narisawa Y, Arase S, et al. Differences in fecal microflora between patients with atopic dermatitis and healthy control subjects. J Allergy Clin Immunol. 2003;111:587-591.

49. Quigley EM. Bacterial flora in irritable bowel syndrome: Role in pathophysiology, implications for management. J Dig Dis. 2007;8:2-7.

50. Si JM, Yu YC, Fan YJ, Chen SJ. Intestinal microecology and quality of life in irritable bowel syndrome patients. World J Gastroenterol. 2004;10:1802-1805.

51. Kassinen A, Krogius-Kurikka L, Makivuokko H, et al. The fecal microbiota of irritable bowel syndrome patients differs significantly from that of healthy subjects. Gastroenterology. 2007;133: 24-33.

52. Tana C, Umesaki Y, Imaoka A, Handa T, Kanazawa M, Fukudo S. Altered profiles of intestinal microbiota and organic acids may be the origin of symptoms in irritable bowel syndrome. Neurogastroenterol Motil. 2010;22:512-515.

53. Hildebrandt MA, Hoffmann C, Sherrill-Mix SA, et al. High-fat diet determines the composition of the murine gut microbiome independently of obesity. Gastroenterology. 2009;137:1716-1724.

54. Ley RE, Backhed F, Turnbaugh P, Lozupone CA, Knight RD, Gordon JI Obesity alters gut microbial ecology. Proc Natl Acad Sci U S A. 2005; 102:11070-11075.

55. Turnbaugh PJ, Hamady M, Yatsunenko T, et al. A core gut microbiome in obese and lean twins. Nature. 2009;457:480-484.

56. Turnbaugh PJ, Ley RE, Mahowald MA, Magrini V, Mardis ER, Gordon JI. An obesity-associated gut microbiome with increased capacity for energy harvest. Nature. 2006;444:1027-1031.

57. Turnbaugh PJ, Backhed F, Fulton L, Gordon JI. Diet-induced obesity is linked to marked but reversible alterations in the mouse distal gut microbiome. Cell Host Microbe. 2008;3:213-223.

58. Kalliomaki M, Collado MC, Salminen S, Isolauri E. Early differences in fecal microbiota composition in children may predict overweight. Am J Clin Nutr. 2008;87:534-538.

59. Schwiertz A, Taras D, Schafer K, et al. Microbiota and short-chain fatty acid in lean and overweight healthy subjects. Obesity (Silver Spring). 2010;18:190-195.

60. Larsen N, Vogensen FK, van den Berg FW, et al. Gut microbiota in human adults with type 2 diabetes differs from non-diabetic adults. PLoS One. 2010;5:e9085.

61. Wu X, Ma C, Han L, et al. Molecular characterisation of the faecal microbiota in patients with type II diabetes. Curr Microbiol. 2010;61(1): $69-78$.
62. Mutlu E, Keshavarzian A, Engen P, Forsyth CB, Sikaroodi M, Gillevet P. Intestinal dysbiosis: A possible mechanism of alcohol-induced endotoxemia and alcoholic steatohepatitis in rats. Alcohol Clin Exp Res. 2009;33:1836-1846.

63. Lupp C, Robertson ML, Wickham ME, et al. Host-mediated inflammation disrupts the intestinal microbiota and promotes the overgrowth of Enterobacteriaceae. Cell Host Microbe. 2007;2:119-129.

64. Hopkins MJ, Macfarlane GT. Changes in predominant bacterial populations in human faeces with age and with Clostridium difficile infection. J Med Microbiol. 2002;51:448-454.

65. Snover DC. Update on the serrated pathway to colorectal carcinoma. Hum Pathol. 2011;42:1-10.

66. Vannucci L, Stepankova R, Kozakova H, Fiserova A, Rossmann P, Tlaskalova-Hogenova H. Colorectal carcinogenesis in germ-free and conventionally reared rats: Different intestinal environments affect the systemic immunity. Int J Oncol. 2008;32:609-617.

67. Kado S, Uchida K, Funabashi H, et al. Intestinal microflora are necessary for development of spontaneous adenocarcinoma of the large intestine in T-cell receptor beta chain and p53 double-knockout mice. Cancer Res. 2001;61:2395-2398.

68. Uronis JM, Muhlbauer M, Herfarth HH, Rubinas TC, Jones GS, Jobin C. Modulation of the intestinal microbiota alters colitis-associated colorectal cancer susceptibility. PLoS One. 2009;4:e6026.

69. Wu S, Rhee KJ, Albesiano E, et al. A human colonic commensal promotes colon tumorigenesis via activation of T helper type $17 \mathrm{~T}$ cell responses. Nat Med. 2009;15:1016-1022.

70. Balamurugan R, Rajendiran E, George S, Samuel GV, Ramakrishna BS. Real-time polymerase chain reaction quantification of specific butyrateproducing bacteria, Desulfovibrio and Enterococcus faecalis in the feces of patients with colorectal cancer. J Gastroenterol Hepatol. 2008;23:1298-1303.

71. Sobhani I, Tap J, Roudot-Thoraval F, et al. Microbial dysbiosis in colorectal cancer (CRC) patients. PLoS One. 2011;6:e16393.

72. Okada H, Kuhn C, Feillet H, Bach JF. The 'hygiene hypothesis' for autoimmune and allergic diseases: An update. Clin Exp Immunol. 2010;160:1-9.

73. Roduit C, Wohlgensinger J, Frei R, et al. Prenatal animal contact and gene expression of innate immunity receptors at birth are associated with atopic dermatitis. J Allergy Clin Immunol. 2011;127: 179-185.

74. Phipatanakul W, Celedon JC, Raby BA, et al. Endotoxin exposure and eczema in the first year of life. Pediatrics. 2004;114:13-18.

75. Like AA, Guberski DL, Butler L. Influence of environmental viral agents on frequency and tempo of diabetes mellitus in $\mathrm{BB} /$ Wor rats. Diabetes. 1991;40:259-262.

76. Wen L, Ley RE, Volchkov PY, et al. Innate immunity and intestinal microbiota in the development of Type 1 diabetes. Nature. 2008;455:1109-1113.

77. Cani PD, Amar J, Iglesias MA, et al. Metabolic endotoxemia initiates obesity and insulin resistance. Diabetes. 2007;56:1761-1772.

78. Cani PD, Neyrinck AM, Fava F, et al. Selective increases of bifidobacteria in gut microflora improve high-fat-diet-induced diabetes in mice through a mechanism associated with endotoxaemia. Diabetologia. 2007;50:2374-2383

79. Szabo G, Bala S. Alcoholic liver disease and the gut-liver axis. World J Gastroenterol. 2010;16:1321-1329.

80. Thuy S, Ladurner R, Volynets V, et al. Nonalcoholic fatty liver disease in humans is associated with increased plasma endotoxin and plasminogen activator inhibitor 1 concentrations and with fructose intake. J Nutr. 2008;138:1452-1455.

81. Sabate JM, Jouet P, Harnois F, et al. High prevalence of small intestinal bacterial overgrowth in patients with morbid obesity: A contributor to severe hepatic steatosis. Obes Surg. 2008;18:371-377.

82. Cani PD, Bibiloni R, Knauf C, et al. Changes in gut microbiota control metabolic endotoxemia-induced inflammation in high-fat diet-induced obesity and diabetes in mice. Diabetes. 2008;57: $1470-1481$. 
83. Cani PD, Possemiers S, Van de Wiele T, et al. Changes in gut microbiota control inflammation in obese mice through a mechanism involving GLP-2-driven improvement of gut permeability. Gut. 2009;58: 1091-1103.

84. Attene-Ramos MS, Nava GM, Muellner MG, Wagner ED, Plewa MJ, Gaskins HR. DNA damage and toxicogenomic analyses of hydrogen sulfide in human intestinal epithelial FHs 74 Int cells. Environ Mol Mutagen. 2010;51:304-314.

85. Hope ME, Hold GL, Kain R, El-Omar EM. Sporadic colorectal cancer - role of the commensal microbiota. FEMS Microbiol Lett. 2005;244:1-7.

86. Payne CM, Crowley-Skillicorn C, Bernstein C, Holubec H, Moyer MP, Bernstein H. Hydrophobic bile acid-induced micronuclei formation, mitotic perturbations, and decreases in spindle checkpoint proteins: Relevance to genomic instability in colon carcinogenesis. Nutr Cancer. 2010;62:825-840

87. Onoue M, Kado S, Sakaitani Y, Uchida K, Morotomi M. Specific species of intestinal bacteria influence the induction of aberrant crypt foci by 1,2-dimethylhydrazine in rats. Cancer Lett. 1997;113:179-186.

88. Ellmerich S, Scholler M, Duranton B, et al. Promotion of intestinal carcinogenesis by Streptococcus bovis. Carcinogenesis. 2000;21:753-756.

89. Backhed F, Ding H, Wang T, et al. The gut microbiota as an environmental factor that regulates fat storage. Proc Natl Acad Sci U S A. 2004;101:15718-15723.

90. Samuel BS, Shaito A, Motoike T, et al. Effects of the gut microbiota on host adiposity are modulated by the short-chain fatty-acid binding G protein-coupled receptor, Gpr41. Proc Natl Acad Sci U S A. 2008;105:16767-16772.

91. Backhed F, Manchester JK, Semenkovich CF, Gordon JI. Mechanisms underlying the resistance to diet-induced obesity in germ-free mice. Proc Natl Acad Sci U S A. 2007;104:979-984.

92. Dumas ME, Barton RH, Toye A, et al. Metabolic profiling reveals a contribution of gut microbiota to fatty liver phenotype in insulinresistant mice. Proc Natl Acad Sci U S A. 2006;103:12511-12516.

93. Food and Agriculture Organization/World Health Organization. Health and nutritional properties of probiotics in food including powder milk with live lactic acid bacteria. Report of a joint FAO/WHO expert consultation on evaluation of health and nutritional properties of probiotics in food including powder milk with live lactic acid bacteria. Basel, Switzerland: World Health Organization; 2001.

94. Falagas ME, Betsi GI, Athanasiou S. Probiotics for prevention of recurrent vulvovaginal candidiasis: A review. JAntimicrob Chemother. 2006;58:266-272.

95. Mshvildadze M, Neu J. Probiotics and prevention of necrotizing enterocolitis. Early Hum Dev. 2009;85:S71-S74.

96. Reiff C, Kelly D. Inflammatory bowel disease, gut bacteria and probiotic therapy. Int J Med Microbiol. 2010;300:25-33.

97. Preidis GA, Versalovic J. Targeting the human microbiome with antibiotics, probiotics, and prebiotics: Gastroenterology enters the metagenomics era. Gastroenterology. 2009;136:2015-2031.
98. Prakash S, Jones ML. Artificial cell therapy: New strategies for the therapeutic delivery of live bacteria. J Biomed Biotechnol. 2005:4-56.

99. Prakash S, Martoni C. Toward a new generation of therapeutics: Artificial cell targeted delivery of live cells for therapy. Appl Biochem Biotechnol. 2006;128:1-22.

100. Gibson GR, Roberfroid MB. Dietary modulation of the human colonic microbiota: Introducing the concept of prebiotics. J Nutr. 1995; 125:1401-1412.

101. Cani PD, Lecourt E, Dewulf EM, et al. Gut microbiota fermentation of prebiotics increases satietogenic and incretin gut peptide production with consequences for appetite sensation and glucose response after a meal. Am J Clin Nutr. 2009;90:1236-1243.

102. Strowski MZ, Wiedenmann B. Probiotic carbohydrates reduce intestinal permeability and inflammation in metabolic diseases. Gut. 2009;58:1044-1045.

103. Rafter J, Bennett M, Caderni G, et al. Dietary synbiotics reduce cancer risk factors in polypectomized and colon cancer patients. Am J Clin Nutr. 2007;85:488-496.

104. Gill SR, Pop M, Deboy RT, et al. Metagenomic analysis of the human distal gut microbiome. Science. 2006;312:1355-1359.

105. Martoni C, Bhathena J, Jones ML, Urbanska AM, Chen H, Prakash S. Investigation of microencapsulated $\mathrm{BSH}$ active lactobacillus in the simulated human GI tract. J Biomed Biotechnol. 2007:13684.

106. Martoni C, Bhathena J, Urbanska AM, Prakash S. Microencapsulated bile salt hydrolase producing Lactobacillus reuteri for oral targeted delivery in the gastrointestinal tract. Appl Microbiol Biotechnol. 2008;81:225-233.

107. Bhathena J, Kulamarva A, Urbanska AM, Martoni C, Prakash S. Microencapsulated bacterial cells can be used to produce the enzyme feruloyl esterase: Preparation and in-vitro analysis. Appl Microbiol Biotechnol. 2007;75:1023-1029.

108. Bhathena J, Martoni C, Kulamarva A, Urbanska AM, Malhotra M, Prakash S. Orally delivered microencapsulated live probiotic formulation lowers serum lipids in hypercholesterolemic hamsters. $J$ Med Food. 2009;12:310-319.

109. Chen H, Ouyang W, Jones M, Haque T, Lawuyi B, Prakash S. In-vitro analysis of APA microcapsules for oral delivery of live bacterial cells. J Microencapsul. 2005;22:539-547.

110. Ouyang W, Chen H, Jones ML, et al. Novel multi-layer APPPA microcapsules for oral delivery: Preparation condition, stability and permeability. Indian J Biochem Biophys. 2009;46:491-497.

111. Urbanska AM, Bhathena J, Martoni C, Prakash S. Estimation of the potential antitumor activity of microencapsulated Lactobacillus acidophilus yogurt formulation in the attenuation of tumorigenesis in Apc(Min/+) mice. Dig Dis Sci. 2009;54:264-273.

112. Li M, Wang B, Zhang M, et al. Symbiotic gut microbes modulate human metabolic phenotypes. Proc Natl Acad Sci US A. 2008;105: $2117-2122$.

\section{Publish your work in this journal}

Biologics: Targets \& Therapy is an international, peer-reviewed journal focusing on the patho-physiological rationale for and clinical application of Biologic agents in the management of autoimmune diseases, cancers or other pathologies where a molecular target can be identified. This journal is indexed on PubMed Central, CAS, EMBase, Scopus

\section{Dovepress}

and the Elsevier Bibliographic databases. The manuscript management system is completely online and includes a very quick and fair peerreview system, which is all easy to use. Visit http://www.dovepress. com/testimonials.php to read real quotes from published authors. 